\title{
"Mensaje a la juventud". Luis Jiménez de Asúa y el movimiento estudiantil opositor a la Dictadura de Primo de Rivera
}

\author{
"Message to youth". Luis Jiménez de Asúa \\ and the student movement opposed \\ to the Primo de Rivera Dictatorship
}

\author{
Gonzalo J. Martínez Cánovas \\ Universidad de Alicante \\ ORCID ID: 0000-0002-5336-3222
}

Recibido: $\quad$ 15/01/2021

Aceptado: $\quad 10 / 10 / 2021$

DOI: https://doi.org/10.20318/cian.2021.6440

Resumen: Durante la Dictadura de Primo de Rivera, el movimiento estudiantil experimentó una serie de cambios tan profundos que le llevaron de su tradicional actitud de atonía a la primera línea de la vida pública española. Sus manifestaciones de disidencia frente al régimen se fundamentaron no solo en su política intervencionista, sino también sobre actitudes subversivas respecto a convenciones y usos sociales ampliamente establecidos. Por otra parte, no pocos de aquellos protagonistas juveniles, así como algunos de los trabajos historiográficos más notables, han considerado a Luis Jiménez
Abstract: During the Primo de Rivera Dictatorship, the student movement underwent a series of changes so profound that they brought it from its traditional atony attitude to the forefront of Spanish public life. His manifestations of dissidence against the regime were based not only on the interventionist policy of the Dictatorship, but also on subversive attitudes towards widely established social conventions and customs. On the other hand, not few of those youthful protagonists, as well as some of the most notable historiographical works, have considered Luis Jiménez de Asúa to be the most

"gjmc2@alu.ua.es 
de Asúa como el más destacado de los catedráticos contestatarios. Titular de la cátedra de Derecho penal de la Universidad Central y considerado entre los ambientes juveniles liberales como un guía espiritual, también Asúa experimentó durante aquella década un profundo proceso de transformación personal. El siguiente artículo se aproxima a este proceso convergente, tomando como marcos de referencia simbólico-cronológicos dos manifiestos representativos del jurista madrileño, tributarios además de dos contextos radicalmente distintos: Impresiones de la Argentina (15/10/1923) y Mensaje a la juventud. Retorno a la ciencia (17/04/1931).

Palabras clave: Luis Jiménez de Asúa; España; movimiento estudiantil; dictadura de Primo de Rivera; universidad. outstanding of the protester professors. $\mathrm{He}$ is a professor of criminal law at the Central University and is considered a spiritual guide among liberal youths. During that decade, Asúa also experienced a deep process of personal transformation. The following article approaches this convergent process, taking as a symbolic-chronological frame of reference two representative manifestos of the Madrid jurist, tributary as well as two radically different contexts: Impressions of Argentina $(15 / 10 / 1923)$ and Message to the Youth. Return to Science (17/04/1931).

Keywords: Luis Jiménez de Asúa; Spain; student movement; Primo de Rivera's dictatorship; university.

\section{Introducción}

La trascendencia de las movilizaciones estudiantiles contra el régimen primorriverista y su contribución en la erosión y caída del sistema monárquico han sido objeto de estudios solventes ${ }^{1}$. Sumido en una profunda revolución de usos y costumbres sociales, durante el transcurso de la década de los años veinte el movimiento juvenil español fue intensificando sus protestas contra las instituciones que constituían los pilares de transmisión del modelo de orden social conservador patrocinado por la Dictadura² ${ }^{2}$. La política educativa autoritaria - materializada especialmente en el trato de favor a las organizaciones estudiantiles católicas- estimuló las primeras manifestaciones disidentes, al tiempo que la figura del desterrado Unamuno fue elevada a símbolo de la resistencia frente al poder dictatorial. Pero el decurso de la década reveló que el activismo juvenil había penetrado en el terreno de lo político con un cariz inequívocamente antidinástico.

\footnotetext{
${ }^{1}$ Como punto de partida conviene citar cuatro trabajos, a pesar de que alguno desborde en cronología o temática el objeto de estudio del artículo. En orden cronológico: Shlomo BenAmi, "Los estudiantes contra el Rey. Papel de la F.U.E. en la caída de la Dictadura y la proclamación de la República", Historia 16, Año I, no. 6 (octubre 1976): 37-47; Genoveva García Queipo de Llano, Los intelectuales y la dictadura de Primo de Rivera (Madrid: Alianza Editorial, 1988); Shlomo Ben-Ami, Los orígenes de la Segunda República Española: anatomía de una transición (Madrid: Alianza Editorial, 1990); Eduardo González Calleja, Rebelión en las aulas (Madrid: Alianza Editorial, 2009).

${ }^{2}$ González Calleja, Rebelión, 100.
} 
Aquel tránsito fue espoleado por el —reducido hasta 1925, creciente desde 1926 y generalizado a partir de $1929^{3}$ - grupo de intelectuales que consideraron inaceptables los fundamentos doctrinales oficialistas y se erigieron como sus opositores irreconciliables. Y dentro del mundo universitario, el joven catedrático Luis Jiménez de Asúa asumió una posición de liderazgo. En un capítulo de su conocido trabajo de 1988, la profesora García Queipo de Llano expuso con notable acierto la orientación del activismo del jurista madrileño: "Es un caso un tanto excepcional. Fue uno de los opositores más valientes y decididos a la Dictadura, pero nunca durante ella se adscribió a una posición política partidista"4; su lucha se extendió, en lo fundamental, en la defensa de la independencia de la Universidad de un lado y en el sustento de actitudes de comportamiento social radicalmente opuestas a las defendidas por el régimen de otro. Su posición en cuestiones de debate público como la eutanasia, el amor libre, el aborto, el matrimonio, la familia, la condición y emancipación femenina o la defensa de un hispanismo de corte liberal-cultural, unido a una enérgica actitud insurgente frente a la élite de poder y su maquinaria de transmisión cultural, lo elevaron a una especie de guía espiritual para el movimiento estudiantil contestatario. Aquello, y su inquebrantable fe en la juventud como motor de cambio social.

Algunos de los más destacados protagonistas del movimiento estudiantil de la época señalaron la significación del jurista en este capítulo. Si Emilio González López subrayó en sus memorias el modo en el que "el mejor maestro" de la Facultad de Derecho de Madrid y "el más liberal" de todos los profesores universitarios de la capital "nos prestó de una manera decidida su apoyo desde el comienzo de la lucha de los estudiantes contra la Dictadura de Primo de Rivera" ${ }^{2}$, y Juan Simeón Vidarte no dudó en calificar al jurista madrileño décadas más tarde como "el líder de la juventud estudiantil”", José López Rey fue el encargado de escribir una "Réplica en nombre de la mocedad" para la publicación de Juventud, en base a una conferencia homónima de Asúa en la Casa del pueblo, el 24 de mayo de $1929^{7}$. Pero quizá las líneas más luminosas de lo que significó el jurista para aquella juventud contestataria se las deba-

\footnotetext{
${ }^{3}$ Genoveva García Queipo de Llano, "Intelectuales y política en la dictadura de Primo de Rivera” (tesis doctoral, Universidad Complutense de Madrid, 1987), introducción.

${ }^{4}$ García Queipo de Llano, Los intelectuales, 517.

${ }^{5}$ Emilio González López, Memorias de un estudiante liberal (1903-1931) (A Coruña: Ediciós do Castro, 1987), 117, 123.

${ }^{6}$ Juan Simeón Vidarte, No queríamos al Rey (Barcelona: Grijalbo, 1977), 202.

${ }^{7}$ Luis Jiménez de Asúa, Juventud. Conferencia de Luis Jiménez de Asúa y réplica de José López-Rey (Madrid: Velasco, 1929).
} 
mos a María Zambrano. Para la entonces joven activista universitaria, lo de Asúa no tuvo parangón entre toda aquella pléyade de insignes referentes con los que contó la intelectualidad española de la época:

Pero entre aquellos «mayores» había alguien intermediario: joven, apasionado, más entusiasta aún que los jóvenes, pues el entusiasmo que traspasa la primera juventud es más intenso que el de la propia juventud [...]. Habían tenido ellos -los jóvenes - la fortuna inmensa de contar con él desde un principio [...]. Ella no conocía a este joven catedrático, lo conoció personalmente como a tantos otros de aquellos hombres un tanto «mitológicos» en la reunión. Pero a este ya se sabía que habían de seguirlo viendo después, contaban con él [...]. Era entre todos el que ya se había puesto en marcha, el que se había movido moviendo a los demás ${ }^{8}$.

Los epígrafes siguientes se aproximan a la convergencia entre la movilización estudiantil contra la dictadura primorriverista y el desarrollo de una circunstancia vital que no solo traspasará toda la década de los veinte para su protagonista, sino que desbordará en consecuencias hacia el resto de su biografía: aquel activismo incansable y su liderazgo entre el movimiento estudiantil, como más tarde su salto a la política republicana y su protagonismo de los años treinta, hunden sus raíces en el profundo proceso de maduración personal que experimentó entonces. Una transformación que, en última instancia, fue la que sostuvo en el tiempo todo un comportamiento insurgente y un pensamiento transgresor en no pocos aspectos relacionados con las conductas y valores predominantes de la época. Al respecto, si las publicaciones de Asúa de finales del diez y principios de la década siguiente están monopolizadas por el estudio de los modernos Códigos penales, la mayor parte de las que firmará los siguientes años albergan un contenido fundamentalmente ético y social.

En las aulas de la Universidad se localiza la zona cero desde donde se proyectará la figura pública que llegará a ser el jurista madrileño en el futuro ${ }^{9}$. Porque su ingreso en las filas del Partido Socialista Obrero Español (PSOE) y su inopinado protagonismo político tras la proclamación de la Segunda República, no se nos presentan del todo inteligibles sin la observación de los años inmediatamente precedentes. Observaremos entonces un proceso de maduración que le llevó del cientificismo tan marcado

\footnotetext{
${ }^{8}$ María Zambrano, "Delirio y destino", OO. CC. VI, coordinado por Jesús Moreno Sanz y edición al cuidado de Goretti Ramírez y Jesús Moreno Sanz (Barcelona: Galaxia Gutenberg, 2014), 871-872.

${ }_{9}^{9}$ Gonzalo J. Martínez Cánovas, “Luis Jiménez de Asúa. El penalista de la retaguardia imposible" (tesis doctoral, Universidad de Alicante, 2020), capítulos 2.5, 3 ,4 y 5.
} 
de sus inicios al compromiso creciente con los problemas de su tiempo, del que contamos con una confesión de 1927 en primera persona:

La vocación por las ciencias del delito y de la pena me hizo desentenderme, durante largos años, de preocupaciones políticas y sociales. A tiempo he comprendido que los técnicos que abjuran de su cualidad ciudadana merecen el más denso menosprecio. El universo íntimo de mi ser se ha colonizado por nuevos pobladores, a los que se deben las páginas de esta obra. El Directorio y los que continúan ahora sus maneras no son ajenos a esta evolución de mi intimidad, que contemplo con extremo regocijo. Algún favor había de hacerme la Dictadura ${ }^{10}$.

De la necesidad vital que tuvo Asúa por vincular política y Derecho y la trascendencia para su dimensión como figura pública, merecen ser destacados, cuanto menos, dos trabajos: el meritorio ejercicio exegético del pensamiento del jurista que llevó a cabo el profesor Sebastián Urbina Tortella en $1984^{11}$, y, más cercano en el tiempo, la biografía "eminentemente penal" de Enrique Roldán Cañizares ${ }^{12}$. En última instancia, aquel compromiso le llevó, para sorpresa de propios y extraños, a la primera línea de la política republicana. Pero, que ingresara en política no significaba que pretendiese hacer carrera en ella. Todo lo contrario, su determinación, como dejó escrito en aquel llamamiento público a la juventud española tres días después de la proclamación del nuevo régimen democrático, era contribuir a la formación de la retaguardia de la República.

\section{Impresiones de la Argentina (15/10/1923)}

El golpe militar del 13 septiembre sorprendió al catedrático madrileño de regreso de Argentina: "Mi llegada a España fue desconsoladora. Yo creí que el Directorio tendría frente a él una vigorosa opinión liberal, y hallé solo apologistas, incluso entre gentes de psique avanzada"13. Era su primer viaje trasatlántico. De la trascendencia que supuso esta irrupción para los círculos académicos y el legado posterior del jurista en el mundo del Derecho penal

\footnotetext{
${ }^{10}$ Luis Jiménez de Asúa, Política. Figuras. Paisajes (Madrid: Historia Nueva, 1927), prólogo.

${ }^{11}$ Sebastián Urbina Tortella, Ética y política en Jiménez de Asúa (Palma de Mallorca: Facultad de Derecho, 1984), 10.

${ }^{12}$ Enrique Roldán Cañizares, Luis Jiménez de Asúa. Derecho penal, República, Exilio (Madrid: Dykinson, 2019), 131.

${ }^{13}$ Jiménez de Asúa, Política, 19.
} 
latinoamericano se han escrito muchas líneas ${ }^{14}$. Durante su estancia en el país de La Plata mostró un interés especial por el movimiento reformista universitario que, desde su epicentro en la Universidad de Córdoba y bajo el impulso decidido de la Federación Universitaria Argentina, se extendía por distintas latitudes del continente como bandera de la democratización y autonomía de la Universidad.

Asúa se propuso con todo empeño que los estudiantes españoles conocieran aquella efervescencia juvenil. La relevancia del momento para el futuro inmediato del movimiento estudiantil español es notable, pues la toma de conciencia cívica de las Asociaciones Oficiales no confesionales, ante el avance del clericalismo tutelado por la Dictadura, concurrió en el tiempo con una aspiración "compartida por estudiantes y profesores, de contribuir a la democratización del país. Ello coincidió con la definitiva llegada a España del movimiento de renovación universitaria latinoamericano, que contó con el apoyo de profesores jóvenes, como Luis Jiménez de Asúa y Felipe Sánchez Román"15. Tanto, que en octubre de aquel mismo año el primero organizó una conferencia en la madrileña Residencia de Estudiantes bajo el epígrafe Impresiones de la Argentina ${ }^{16}$. Fue el inicio de lo que acabó constituyendo un ritual con todos y cada uno de sus viajes trasatlánticos: mensajes de confraternización entre ambos movimientos y soflamas en favor de la movilización del estudiantado español. Jiménez de Asúa se convenció de su papel de mediador cultural. No en vano, el fortalecimiento de las relaciones culturales entre los movimientos estudiantiles de uno y otro lado del Atlántico se cimentó, durante aquella década, sobre una identificación generacional contestataria frente a determinados valores y hábitos tradicionales que exigió del compromiso político de sus protagonistas. Y en el impulso, estímulo y consolidación del diálogo trasatlántico, el papel de mediación de algunos intelectuales liberales fue no-

${ }^{14}$ Por citar dos artículos de referencia entre una generosa literatura: Manuel de Rivacoba y Rivacoba, "El Derecho penal en el mundo hispánico antes y después de Jiménez de Asúa", Revista de la Facultad de Derecho de la Universidad Complutense, 11 (junio, 1986), 263-277; Enrique Roldán Cañizares, "De Berlín a Buenos Aires: el trasplante del método de casos en Argentina", La memoria del jurista español, ed. Manuel Ángel Bermejo Castrillo (Madrid: Dykinson, 2019): 383-416.

${ }^{15}$ González Calleja, Rebelión, 98.

${ }^{16}$ Asúa no solía escribir sus disertaciones; se limitaba a trazar una especie de esquemaguía con el que estructuraba su intervención. En esta concreta, las ideas matrices no dejan lugar a la duda respecto de sus intenciones: el estado de la Universidad en Argentina, el movimiento renovador de Córdoba, la intensa vida cultural de sus estudiantes y el contraste y decepción con «la apatía de aquí»... Cfr. AFPI, ALJA-434-12: Conferencia de Luis Jiménez de Asúa: Impresiones de la Argentina, (15-10-1923) [manuscrito]. Por lo demás, algunos periódicos como el Adelanto del 23 de octubre se hicieron eco del acto de salutación. 
table. La historiadora argentina Luciana Carreño, buena conocedora de las redes intelectuales entre España y Latinoamérica, ha escrito al respecto que:

Luis Jiménez de Asúa fue colaborador de la revista Sagitario y reconocido públicamente como guía espiritual en las páginas de El Estudiante. En la década del veinte realizó tres viajes a la Argentina en 1923, 1925, y 1929 [en los cuales] pudo ejercer una función mediadora a doble escala. Así, frente a los auditorios argentinos, además de disertar sobre su especialidad en ciencia penal, actuó como propagandista de una versión progresista del hispanoamericanismo propia de los opositores al régimen de la dictadura, y paralelamente de regreso a España difundía las impresiones de sus viajes especialmente entre las juventudes universitarias entre las cuales gozaba de gran popularidad ${ }^{17}$.

Si alguien albergaba todavía alguna duda sobre las intenciones del jurista para con el movimiento estudiantil, quedaron despajadas con el segundo de sus viajes. El 8 de diciembre de 1924 llegó a Perú. Para entonces era asiduo colaborador de La Prensa de Buenos Aires, proyectaba una imagen de marcado perfil progresista y gozaba ya de cierto reconocimiento internacional como penalista. Su llegada al país andino respondía a la doble invitación de su Gobierno para que participara, de un lado, en el III Congreso Científico Panamericano, y de otro, en los actos programados con motivo del Centenario de Ayacucho y la independencia de Perú.

Poco antes el Directorio militar había declinado participar en unos actos donde se conmemorarían unas cicatrices que un siglo más tarde todavía dolían ${ }^{18}$. Descartada esta vía, la diplomacia peruana se dirigió entonces a un grupo de intelectuales y artistas españoles de reconocido prestigio internacional. La mayoría de ellos declinaron la oferta. Todos, excepto el periodista Julio Camba y los profesores Jiménez de Asúa y Vicente Gay y Forner ${ }^{19}$. Catedráticos ambos pero representantes desde la intelectualidad de dos formas antagónicas de entender el hispanoamericanismo, los dos buscaron también escenarios más adecuados con los que entrar en contacto con los ambientes intelectuales peruanos. En el caso del jurista destacó su cercanía con el académico Edwin Elmore, al que acompañó entonces en un torneo poético-ideo-

${ }^{17}$ Luciana Carreño, "Relaciones culturales hispanoargentinas en la década del veinte. Universitarios, intelectuales y maestros, un diálogo a través de las revistas estudiantiles", Revista Circunstancia, Año X, 28, (mayo, 2012), 6/10.

${ }^{18}$ Una lectura más extendida del episodio en: Ascensión Martínez Riaza, "Las cicatrices de Ayacucho. España en la celebración de un centenario hispanoamericano", Anuario IEHS: Instituto de Estudios histórico sociales, 32, no 1 (2017): 179-204.

${ }^{19}$ Luis Jiménez de Asúa, El Derecho penal en la República del Perú, (Universidad de Valladolid: publicaciones de la Sección de Estudios Americanistas, serie 2ª , número III, 1926), introducción. 
lógico que se convirtió en el germen de lo que dos años más tarde significó, por un disparo del poeta José Santos Chocano, el asesinato del propio Elmore.

Muchas líneas le dedicaría después nuestro protagonista al crimen de su amigo peruano. Pero más allá de su participación en los fastos del Centenario, lo más interesante de aquel viaje para la cuestión que nos ocupa fue su empeño por confraternizar con los universitarios andinos. Al respecto, aprovechó el escaso tiempo libre que le quedó para impartir dos conferencias sobre Derecho penal en la Universidad limeña de San Marcos, precedidas del correspondiente mensaje de sus alumnos españoles ${ }^{20}$. A su regreso a España, el 10 de enero, el catedrático se llevó consigo la respuesta de sus homólogos americanos. Mientras que Gay y Forner se entrevistaba con Alfonso XIII para ponerle al día de los pormenores del viaje, para nuestro protagonista significó una nueva oportunidad de arengar a los estudiantes españoles y reclamarles compromiso frente a la instrumentalización política de la Universidad. Así lo hizo el 7 de febrero:

Al volver del Perú -dijo- veo con pupila dolorosa el espectáculo de vuestras discrepancias [...]. Se avecinan tal vez días preñados de grandes responsabilidades. Se habla de reformas de la enseñanza y de cuestionarios y textos únicos. Que la lucha se mantenga en nobles rangos espirituales de discusión, pero que cada uno sustente su criterio. Yo estoy persuadido - terminó diciendo- que vosotros sabréis cumplir vuestro deber ${ }^{21}$.

Como era de esperar, el Directorio comenzó a poner trabas a los viajes trasatlánticos del jurista, consciente de que traspasaban los motivos oficiales por los que se solicitaban y de las repercusiones negativas para su imagen, más si cabe por la prodigalidad que mostraba en sus ataques a través de la prensa argentina. No en vano, por similares razones en febrero del año anterior el dictador había decidido confinar en Fuerteventura a su admirado Unamuno.

\section{En el nombre de Unamuno}

Camino de su destierro, la madrugada del 21 de febrero de 1924 Miguel de Unamuno llegó a la madrileña Estación del Norte. La presencia del profesor vasco en la capital de España incomodaba a las autoridades, recelosas por

${ }^{20}$ Las conferencias titularon: Las bases de la legislación penal del porvenir y Homicidio piadoso, comentario a uno de los artículos del nuevo Código penal peruano.

${ }^{21}$ El Sol, 9 de febrero de 1925. 
la posible magnitud de las manifestaciones de apoyo a tan insigne figura. Para las diez de la mañana del día 22 debía continuar su itinerario rumbo a Cádiz, donde le esperaba el polifacético periodista Rodrigo Soriano. Pero a primera hora de la mañana corrió por los pasillos de la Facultad de Derecho de la Universidad Central la noticia de la inminente partida de Unamuno. La espantada estudiantil para despedirlo fue generalizada. Asúa, que conocía y admiraba a Unamuno, no tardó en escribirle una carta lamentándose por no haber llegado a tiempo para despedirse de él personalmente ${ }^{22}$. Los alumnos más comprometidos con la causa decidieron expresar públicamente su disconformidad con la decisión del dictador y "eligieron" para ello la clase de Derecho del joven catedrático. Del episodio nos han quedado las memorias de Emilio González López ${ }^{23}$, discípulo confeso de Asúa que pocos meses después comenzó a organizar - junto con un reducido grupo de estudiantes prorrepublicanos- la Unión Liberal de Estudiantes (ULE), al objeto de reimpulsar las protestas contra la Dictadura y disputarle a las organizaciones católicas su predominio en la Universidad madrileña.

De cualquier manera, lo sustancial del caso fue que el profesor vasco se convirtió desde entonces en el símbolo fundacional de la resistencia antidictatorial. Quedó en la memoria colectiva como un punto de inflexión de la lucha contra el régimen. Así lo consideró también Asúa durante el resto de su vida. En una entrevista que concedió a Radio Televisión Argentina cuatro décadas más tarde, le preguntaron si recordaba el momento en el que decidió intervenir en la política nacional. Su respuesta fue instantánea: cuando Primo de Rivera trató de doblegar a la Universidad, cuando desterró a Unamuno, "en aquel momento me obligaron un poco a hacer política [o mejor] tratábamos de evitar que se hiciera política a costa de la Universidad o contra la Universidad... y es ahí como yo empecé" 24 . Aquella lucha, como se sabe, acabó extendiéndose a un plano más general bajo la bandera de la democracia y la modernización del país.

Para finales de 1924 la ULE ya era una realidad y pronto asumiría el peso de las movilizaciones estudiantiles. Su carta de presentación llegó en

${ }^{22}$ Icíar Fernández Marrón, "Cartas de cuatro juristas republicanos a Miguel de Unamuno (1920-1936)", Cuadernos de la cátedra de Miguel de Unamuno, 33 (Universidad de Salamanca, 1998): 193-218. El artículo recupera siete cartas personales entre ambos, la última de ellas escrita por el profesor madrileño el 11 de marzo de 1936.

${ }^{23}$ González López, Memorias, 125-129.

${ }^{24}$ Luis Jiménez de Asúa, "Gente", entrevista de Augusto Bonardo, Archivo Histórico de Radio Televisión Argentina, 7 de octubre de 1960. Audio, 24:50. http://www.archivorta.com.ar/ asset/gente-5. 
una fecha muy señalada: la repatriación en marzo de 1925 de los restos del escritor granadino y hermano generacional de Unamuno, Ángel Ganivet. A iniciativa estudiantil se le preparó un homenaje en la Universidad Central, previo paso del traslado a su tierra natal. Los días precedentes, la disputa mediática por adueñarse del pensamiento de Ganivet había sido bastante agria. Pero fue en el Paraninfo de la Universidad madrileña donde el homenaje tomó el cariz de protesta política. A mediodía del sábado 28 comenzó una ceremonia de cuya repercusión pública daba buena cuenta el distinguido elenco de asistentes: Ministerio de Estado, Cuerpos consulares y diplomáticos, Ayuntamientos de Madrid y Granada, Diputación provincial, Sociedad económica... En representación del Ateneo de Madrid estaban llamados a participar Gregorio Marañón y Jiménez de Asúa. En este punto, resulta poco cuestionable la afirmación del dirigente falangista David Jato, que en su obra de referencia sostuvo que "el más destacado por su vehemencia fue Jiménez de Asúa, muy en contacto con sus alumnos rebeldes"25. Para entonces el jurista colaboraba activamente en la distribución de las célebres Hojas Libres que, desde París y de la mano de distinguidos exiliados, intentaban agitar la opinión pública nacional.

En su intervención Asúa se encargó de subrayar la carga política del homenaje en un momento en el que, en su opinión, no cabía mantenerse en la ambigüedad. De la cobertura de $A B C$ a las palabras de Asúa: "En España corren instantes en que hay que definir problemas. La extrema derecha nos dice que no hay, ni debe haber, luchas entre izquierdas y derechas, porque tal lucha es arcaica; pero no obstante cree el orador, que hay que volver a resucitar viejos conceptos. Ahora hay que decir: 'Somos progresistas'”26. Y para la juventud, el privilegio de obligación —en el sentido más orteguiano del término- del compromiso con la realidad de España:

Lo que importa en estos momentos es señalar el hecho de que sean los estudiantes los que hayan tomado la iniciativa de rendir homenaje a Ganivet [...]. Los estudiantes todos son, además de estudiantes, un conglomerado humano, y hacen mal los que estiman que no deben ocuparse de los problemas de arte o de política. [Para terminar, entre grandes aplausos]:” ¡Somos progresistas, somos liberales!”27.

Como colofón al desplante se preparó un golpe de efecto: la distribución entre los asistentes de una carta escrita por Unamuno. Asúa convino

\footnotetext{
${ }^{25}$ David Jato, La rebelión de los estudiantes (Madrid: Imp. Romero-Requejo, 1968), 56.

${ }^{26} A B C, 29$ de marzo de 1925.

${ }^{27}$ El Sol, 30 de marzo de 1925.
} 
con los cabecillas de la ULE el momento en el que se leería ante la multitud que abarrotaba el Paraninfo. A pesar de lo accidentado del episodio ${ }^{28}$, la jornada terminó con gritos estudiantiles dando mueras al rey y al dictador y vivas al profesor vasco. Lejos todavía de lo que sucedería a partir de 1928, la ULE inició durante los meses siguientes una serie de movilizaciones como protesta por la puesta de largo de la Ley de Reforma Universitaria impulsada por el Ministro de Instrucción Pública Eduardo Callejo, al tiempo que intelectuales como Marañón, Azaña, Pérez de Ayala, Rodrigo Soriano o el propio Jiménez de Asúa intensificaban sus protestas contra el régimen. Al respecto de la trayectoria del jurista madrileño, la primavera de 1926 requiere una nueva parada.

La mañana del 24 de abril se inauguró en el parque de El Retiro un monumento en honor a Santiago Ramón y Cajal. Con asistencia incluida de Alfonso XIII, el discurso del dictador fue contestado con estruendosos abucheos por las huestes estudiantiles. Su paciencia se vio superada cuando conoció que se estaba preparando para aquella misma tarde un homenaje paralelo de estudiantes y ateneístas, comandados por el "triunvirato de enlace" Marañón-Jiménez de Asúa-Pérez de Ayala. El rumor corrió por todo Madrid y la expectación creció por momentos a pesar de las amenazas de las autoridades gubernativas. Marañón al frente de un grupo de estudiantes de Medicina, Asúa delante de los de la Facultad de Derecho, intelectuales, miembros distinguidos del Ateneo: "Los manifestantes no ocultamos nuestro ademán de enemigos del régimen imperante y exteriorizamos con desenfado las personales convicciones"29. La reacción inmediata del marqués de Estella se tradujo en Decreto para el nombramiento de una nueva Junta directiva del Ateneo. El joven catedrático continuaba acumulando méritos para recibir una sanción ejemplarizante. El régimen, por su parte, tan solo esperaba la ocasión propicia, que no tardó en llegar.

\section{Una breve temporada en Chafarinas}

La tarde en que un Tribunal tenía que resolver en la Facultad de Filosofía de la Universidad Central el nombramiento del único aspirante a ocupar la cátedra de Unamuno, una multitud de alumnos se personó a las puertas del

${ }^{28}$ Además de su ya citada Memorias, Emilio González López evocó aquel acontecimiento en: El espíritu universitario (Madrid: Javier Morata, 1931), 82-84.

${ }^{29}$ Luis Jiménez de Asúa, Notas de un confinado (Madrid: Mundo Latino, 1930), 46. 
recinto en señal de protesta. Los estudiantes no iban solos: les acompañaban Jiménez de Asúa y otro gran amigo y admirador del pensador vasco: el profesor de Farmacia José Giral ${ }^{30}$. Por su condición de catedráticos, ambos exigieron estar presentes en el acto. El Tribunal, temeroso, aplazó su decisión para el día siguiente, no ya en la Universidad sino en dependencias del Ministerio de Instrucción Pública. Era 29 de abril, de mañana, y algunos estudiantes encabezados por el propio Asúa trataron de asistir a una votación que se presumía pública, pero la policía impidió el acceso de la mayoría de ellos. Algunos alumnos lograron burlar la vigilancia y asistieron junto a nuestro protagonista a la proclamación del nuevo titular de la cátedra de Griego de la Universidad de Salamanca.

Lejos de desaparecer, las protestas devengaron en disturbios en los alrededores del Ministerio, respondidos por las fuerzas de orden público con cargas policiales y la detención de seis alumnos. Desde el golpe militar se había endurecido el empleo de medios de fuerza para neutralizar las manifestaciones de disidencia ${ }^{31}$. Aquella misma mañana el catedrático madrileño mostró su indignación ante sus alumnos con unas detenciones que juzgó arbitrarias, desproporcionadas y coercitivas de las libertades individuales y públicas. Aún más: alentó a los estudiantes a continuar con las protestas. Cuando ya de noche la incertidumbre por la suerte de los jóvenes detenidos le llevó hasta la Dirección General de Seguridad, la respuesta gubernamental llegó en forma de orden de confinamiento en las Chafarinas. Para entonces las autoridades ya conocían los disturbios acaecidos en el aula del jurista y, para el Gobierno, la decisión estaba más que justificada: Asúa era el verdadero inductor de los desórdenes estudiantiles y además un incorregible reincidente: "Repetidamente, tanto en España como fuera de España, el Profesor de la Universidad Central Don Luis Jiménez Asúa, viene excitando los ánimos contra el Gobierno, difamando su obra en el ejercicio de su Cátedra, moviendo pasiones y provocando divisiones entre los estudiantes" ${ }^{32}$. A la mañana siguiente el catedrático tomaba un tren hacia Málaga y desde allí, el 3 de mayo, partía en barco rumbo a Melilla.

${ }^{30}$ De la relación de Giral con Unamuno y la oposición política del primero contra la dictadura de Primo de Rivera: Julián Chaves Palacios, “Oposición política a la monarquía de Alfonso XIII. José Giral y los republicanos en la Dictadura de Primo de Rivera”, Hispania no 252 (eneroabril, 2016): 159-187.

${ }^{31}$ Manuel Ballbé, Orden público y militarismo en la España constitucional (1812-1983) (Madrid: Alianza Editorial, 2ª ed., 1985), 306.

${ }^{32}$ AGUCM P-0555, 7, Expediente de Luis Jiménez de Asúa, Archivo General UCM. Fragmento de la Real orden que fundamentaba la decisión del Gobierno. 
El día 5 llegó a las Chafarinas junto con el publicista Arturo Casanueva y Salvador María Vila, por aquel entonces un jovencísimo doctor de Filosofía discípulo de Unamuno. En la isla les esperaba el periodista Francisco de Cossío. Con su destierro Asúa ipor fin cumplía una vieja aspiración moral! Así se lo había confesado al propio Unamuno en correspondencia de octubre de 1924: "Yo trabajo sin desperdiciar ocasión, contra esta inútil gente que nos desgobierna [...]. Yo creo que no seremos dignos hasta que esta canalla inmoral y soez nos meta en la cárcel"33. Pero las protestas por el confinamiento del jurista, en varios frentes, no se hicieron esperar.

Desde la de Derecho los disturbios se extendieron a otras Facultades; en la de Medicina un grupo de estudiantes intentó agredir al general Martínez Anido, de visita circunstancial en el hospital de la Facultad. A las movilizaciones se sumaron Universidades no sólo de España, sino también del otro lado del Atlántico. También el Ateneo de Madrid respondió al extrañamiento de su insigne socio emitiendo una nota de protesta, cuya publicidad se encargó de bloquear la censura. Intelectuales como Luis Araquistáin, Julio Álvarez del Vayo o Américo Castro, profesores como Fernando de los Ríos, Mariano Ruiz-Funes o José Antón Oneca... aquellos primeros días de mayo fueron muchos los que alzaron la voz contra los confinamientos del Gobierno. Con todo, apenas dos semanas después se levantó la pena a los confinados de las Chafarinas. Lejos de desaparecer, los desencuentros entre la Dictadura y Asúa se prodigaron en régimen de ordinario.

\section{Una huelga que bien vale una sanción}

Sin ir más lejos, apenas mes y medio después de regresar de Chafarinas el catedrático dormiría una semana en la Modelo de Madrid tras negarse a hacer efectivo el traspaso de poderes a la nueva Junta del Ateneo, nombrada el 25 de junio en una rápida y hábil maniobra del marqués de Estella, que supo instrumentalizar el conato de levantamiento del día anterior para intervenir la institución. El 7 de julio una representación de la nueva Junta llegó al no 21 de la calle del Prado para tomar posesión del cargo. Encarcelado Marañón -Presidente de la Junta- por los sucesos de la Sanjuanada, y ausente Pittaluga -Vicepresidente-, de viaje en Latinoamérica, Asúa quedó provisionalmente al frente de la institución. El jurista se negó a obedecer el Real Decreto y la Junta oficialista tuvo que regresar junto con la policía,

\footnotetext{
${ }^{33}$ Fernández Marrón, Cartas de cuatro juristas, 201.
} 
desencadenándose entonces una algarada que terminó con el arresto del catedrático y su posterior ingreso en prisión junto con otros cinco ateneístas ${ }^{34}$. El propio Unamuno no tardó en escribirle una carta a nuestro protagonista felicitándole por su "noble actitud cuando lo del atraco del Ateneo"35. A la vista de los resultados, islas Chafarinas y Modelo de Madrid resultaban dos instrumentos estériles.

Durante la primavera del siguiente año el jurista viajó a Asturias al objeto de impartir una serie de conferencias sobre la figura jurídica del estado de necesidad como eximente de responsabilidad penal. El tema y el momento no parecían producto de la casualidad. El Principado era entonces un escenario caliente: aquel fue "el año de la huelga de los mineros asturianos" ${ }^{36}$, que protagonizaron una serie de movilizaciones que no habían conocido igual desde el comienzo de la Dictadura. En lo personal, de nuevo "sufrí la imputación de haber defendido ante los obreros asturianos la facultad que asiste al hambriento para hurtar o robar con el fin de no morir de inanición"37. Pero fue en marzo de 1928 cuando su visita a Murcia adquirió una trascendencia pública extraordinariamente mayor. El contexto general se enmarca en el tránsito de la reivindicación corporativa a la protesta política estudian$\mathrm{til}^{38}$, el episodio desencadenante fue la sanción gubernamental por las dos conferencias que impartió Asúa en la capital levantina y su efecto directo la convocatoria de la primera huelga de 24 horas convocada por la Federación Universitaria Escolar (FUE).

El joven catedrático fue invitado por la Federación Murciana de Estudiantes para actuar como mantenedor en el Certamen Nacional de Estudiantes. Con el fin de sacar el máximo partido a su visita, el jurista murciano y amigo personal de Asúa, Mariano Ruiz-Funes, le organizó dos conferencias en la Universidad de Murcia. La expectación en tierras murcianas fue mayúscula. Cientos de estudiantes le recibieron a su llegada a la Estación del Carmen. Más tarde, la gran afluencia de público dejó pequeño un teatro Romea donde el discurso del jurista no defraudó: "No podemos excluir al estudiante de la preocupación de hombre político [...]. La juventud es pujanza y el ideal,

${ }^{34}$ Fernando Soldevilla, El Año Político (Madrid: Imprenta y encuadernación de Julio Cosano, 1927): 252-253.

35 Vicente Bécares Botas, “Una carta desconocida de Unamuno a Jiménez de Asúa”, Ínsula no 493 (1987), 3.

${ }^{36}$ Manuel Tuñón de Lara, El movimiento obrero en la historia de España (Madrid: Taurus, 1972), 780.

${ }^{37}$ Jiménez de Asúa, Política, prólogo.

${ }^{38}$ González Calleja, Rebelión, 110. 
rebeldía. No hay nada que bata la mente del joven como el corazón. Y el corazón está en la izquierda. El joven tiene el deber de ser rebelde"39. Delante de autoridades civiles y militares de primer rango, Asúa no perdió la ocasión de reclamar de nuevo el compromiso político, el inconformismo y la beligerancia estudiantil para cambiar el lema tradicionalista Dios. Patria. Rey "por este otro, henchido de futuro: Juventud. Progreso. Rebeldía"40. A estas alturas, a nadie extrañaba este tipo de discursos en el profesor madrileño. Pero tanto más difícil de digerir para la moral conservadora eran sus ideas sobre cuestiones como el amor libre, el aborto, la sexualidad o la eutanasia.

Sin ir más lejos, hacía tan solo unos días que el anfiteatro de la Facultad de Medicina de Madrid se había abarrotado con 4.000 jóvenes entusiastas para escucharle hablar sobre El aspecto jurídico de la Eugenesia y de la Maternidad consciente. Fue el 9 de febrero. Ligado al problema eugenésico, el debate sobre la maternidad consciente levantaba en nuestro país profundas sensibilidades. Se trataba de un problema de hondas raíces económico-culturales del que Asúa desarrolló un discurso netamente emancipador. Había que desterrar la idea del "deber" — no legislado pero profundamente enraizado en la sociedad española- de las mujeres de ser madres. La maternidad era un derecho y, en consecuencia, debía ser consciente, voluntaria y fundamentada en "dos causas de indestructible fortaleza: la salud de la madre y el bienestar de la progenie" ${ }^{41}$. Partiendo del principio de derecho inalienable de la mujer con su cuerpo, la ley debía regular los casos en los que no solo se permitieran, sino que se ampararan desde el Estado, determinadas medidas esterilizadoras y abortivas.

Sus palabras fueron el prólogo de la suspensión del ciclo. Los clérigos que formaban parte del cartel de conferencias marcharon en retirada, los medios católicos y conservadores de la capital levantaron sus denuncias contra lo que consideraron un episodio inaceptable de subversión y pornografía y el régimen no tardó en prohibir la celebración del resto del programa. En palabras del joven profesor, "temieron al fracaso ante aquel público joven, pujante y liberal [en una hora en que] ganan más terreno los hombres de izquierda, mientras pierden sus trincheras las derechas. No les convenía la notoria comprobación de la decadencia de sus ideales"42. Ciertamente, con aquellas jornadas se pretendía dar el salto del debate teórico a la opinión

\footnotetext{
${ }^{39}$ El Liberal, ed. Murcia, 7 de marzo de 1928.

${ }^{40}$ Así terminaba el manuscrito que preparó para la ocasión, bajo el elocuente título "La juventud y su misión". FPI-ALJA-436-9, p. 7.

${ }^{41}$ Jiménez de Asúa, Libertad de amar y derecho a morir (Madrid: Historia Nueva, 1929), 59.

${ }^{42}$ Ibid., 8.
} 
pública del país sobre cuestiones tabús relacionadas con la sexualidad, al tiempo que para sus detractores resultaban inaceptables unas propuestas que consideraban subversivas para el orden familiar y social ${ }^{43}$. Aquel fue el cariz sobre el que caminará el debate eugenésico en la España de la época.

Lejos de amedrentarse por la contraofensiva católica, nuestro protagonista regresó a vueltas con la cuestión eugenésica en su conferencia murciana del 7 de marzo, a la que tituló Aspectos jurídicos de la condición humana. No eran ni mucho menos las primeras incursiones de Asúa como criminalista en el área médico-social. Sus primeras observaciones al respecto habían aparecido publicadas en 1918 en el número 1 de la Revista de Ciencias Jurídicas y Sociales de la Facultad de Derecho de Madrid, con un artículo en el que diseccionó las políticas de "higiene racial" de Estados Unidos ${ }^{44}$. En aquel momento, si bien arremetió contra la prohibición legislativa del matrimonio entre enfermos mentales o contra la obligatoriedad de obtener certificados prenupciales en algunos estados norteamericanos, se mostró vacilante respecto a sus programas de esterilización: en ningún caso - pues "la herencia psicológica no está comprobada" - para los delincuentes por muy peligrosos que se mostrasen para la sociedad, pero sí en enfermos mentales o psíquicos para los que la Medicina diagnosticara la transmisión de su "legado maldito". Pronto se percataría del peligro que importaba dejar aquella puerta abierta para acabar rechazando, de plano, la práctica de cualquier sistema de "selección racial" desde los poderes del Estado.

El contexto general del período de entreguerras nos sitúa en un ambiente en el que los movimientos eugenésicos alcanzaron una gran pujanza. En Alemania, una publicación de 1920 puso en el centro del debate de la comunidad científica las teorías de "higiene de las razas": Die friegrabe der Vernichtung lebensunwerten Lebens ${ }^{45}$, obra conjunta del veterano penalista Karl Binding y del psiquiatra Alfred Hoche. En palabras de nuestro protagonista, "tantas meditaciones hice en su torno, que, poco tiempo después de impreso, publiqué un artículo de ese tema en la Revista de Ciencias Jurídicas y Sociales [...] bajo el título La autorización para exterminar a los seres humanos desprovistos de valor vital"46. Es conocido que en las décadas precedentes a la Gran

${ }^{43}$ Marie-Aline Barrachina, "Maternidad, feminidad, sexualidad. Algunos aspectos de las primeras jornadas eugénicas españolas (Madrid, 1928-Madrid, 1933)", Hispania, LXIV/3, no 218 (2004), 1008.

${ }^{44}$ Luis Jiménez de Asúa, "La esterilización de los anormales y delincuentes incorregibles", Revista de Ciencias Jurídicas y Sociales no 1 (enero-marzo, 1918): 23-38.

${ }^{45}$ En castellano: La autorización para exterminar las vidas sin valor vital.

${ }^{46}$ Luis Jiménez de Asúa, Endocrinología y Derecho penal. Eutanasia y Homicidio por compa- 
Guerra las propuestas raciales y de homogenización étnica venían haciendo fortuna en muchos países occidentales, pero en Alemania la publicación de la obra de los dos eruditos alemanes fue un paso más allá y penetró profundamente en el pensamiento de toda una generación sumida en un ambiente nacional propicio y receptivo ${ }^{47}$. En sus publicaciones Asúa subrayó que las tesis de Binding y Hoche en Alemania, como ocurría con las de Filippo Grispigni en Italia, las de Charles Binet-Sanglé en Francia o los programas de esterilización norteamericanos, implicaban el reconocimiento de un fin del Estado en la eliminación de las "vidas sin valor"48. En su opinión, el derecho a la muerte digna del individuo podía justificar la práctica eugenésica, pero en ningún caso esta última podía constituir una amenaza para la vida en forma de instrumento de prevención o de "higiene" de la comunidad.

Regresando a su intervención en la Universidad de Murcia, la nueva ofensa a la moral tradicional-católica tuvo entonces una respuesta más contundente. A la maquinaria mediática de El Debate y El Siglo Futuro le acompañó esta vez la decisión del Ministro Callejo de instruir un expediente que respaldara una dura sanción para el "incorregible" profesor. A pesar de las presiones que llegaron desde Madrid, José Loustau, Rector de la Universidad de Murcia, propuso el sobreseimiento del caso al no hallar prueba alguna para las infracciones de las que se acusaba al jurista ${ }^{49}$. Tampoco el movimiento estudiantil estaba dispuesto a dejar solo a uno de sus referentes. Pronto comenzaron las protestas y la cuestión se convirtió en un problema incómodo para las autoridades: si Asúa se quedaba sin sanción, los sectores conservadores lo considerarían un ultraje y los progresistas una victoria ante el propio régimen; por el contrario, la aplicación de una sanción ejemplarizante, en vista de las movilizaciones estudiantiles, podía ser la llama que prendiera la hoguera de las protestas sociales.

El 7 de abril, el Director General de Enseñanza comunicó al Rector de la Universidad Central la sanción: un mes de empleo y sueldo. Exigua san-

sión. Dos conferencias pronunciadas en la Facultad de Derecho de la Universidad de Montevideo, (Montevideo: Anales de la Universidad, Imprenta Nacional, 1927), 46.

${ }^{47}$ Autores como Henry Friedlander, Fredric Wertham o Ernst Klee han subrayado la influencia de esta obra para los fundamentos del régimen nazi en sus programas de "eutanasia forzada" y en su proyecto posterior de la Solución final. Citando al último de ellos, Juan Jesús Mora Molina le dedicó en una obra de 2002 un capítulo bajo el elocuente título «Binding y Hoche o el embrión del holocausto»: Juan Jesús Mora Molina, Derecho a la vida y permiso para destruir «vidas sin valor», (Sevilla: Aconcagua Libros, 2002), 55 y ss.

${ }^{48}$ Cfr. Jiménez de Asúa, Endocrinología, 65-66.

${ }^{49}$ Luis Valenciano Gayá, El Rector Loustau y la Universidad de Murcia (Madrid: Academia Alfonso X el Sabio, 1979), 80-81. 
ción, de donde se presumía el deseo de Callejo de cubrir expediente y cerrar capítulo. El cálculo, a tenor de los acontecimientos que se sucedieron, fue del todo erróneo. En la Universidad Central las protestas devinieron en violencia y las autoridades académicas, incapaces de contener el ímpetu estudiantil, y "en evitación de un posible día de luto" ${ }^{50}$, suspendieron las clases durante cinco días. A la cabeza de los disturbios estuvo la sección madrileña de la FUE, nacida dos años antes de entre los restos de las Asociaciones Profesionales, con el propósito renovado de disputarle la hegemonía de la representación estudiantil a las organizaciones católicas. No en vano, para el 27 de mayo la FUE convocó su primera huelga de 24 horas en respuesta por la sanción al catedrático madrileño. Los estudiantes acompañaron las protestas con una imaginativa iniciativa: un álbum con miles de firmas y una simbólica recolecta equivalente al sueldo perdido por el profesor; algo que no sólo dejaba sin efecto la pena, sino que suponía una afrenta más para el Gobierno.

El germen del conjunto de asociaciones que compusieron la nueva organización había sido la Asociación Profesional de la Facultad de Derecho de la Universidad Central. Entre sus fundadores y como Secretario General se encontraba González López, por entonces ayudante de cátedra de Asúa, que consideró aquel episodio un punto de inflexión para el movimiento contestatario estudiantil en el que "las organizaciones escolares estaban ya fuertes y disciplinadas. Comenzaba a difundirse por la masa estudiantil el sentimiento corporativo de responsabilidad. Los problemas de la enseñanza eran nuestra aguda preocupación" ${ }^{\prime 1}$. La FUE se convirtió en un agente de extraordinaria influencia social y en la corporación estudiantil hegemónica hasta 1933. La agitación universitaria ya no daría tregua al régimen.

No en vano, como expresó en 1978 Shlomo Ben-Ami, "after launching its first strike in March 1928 in support of a lecture by Jiménez de Asúa on sexual matters, the FUE embarked upon a struggle against anogher Churchsponsores measure: Article 53 of the Callejo reform"52. En mayo comenzaron las protestas contra el Decreto-Ley para la reforma de los estudios universitarios. El punto de mayor fricción era el controvertido artículo 53 por el que se validaban las titulaciones universitarias de colegios católicos como el jesuita Deusto y el agustino de El Escorial, sin más formalidad que la presencia de un catedrático de la Universidad pública en la celebración de los

\footnotetext{
${ }^{50}$ AGUCM P-0555, 7, 96 y ss. Acuerdo del Consejo Universitario de 28 de marzo de 1928.

${ }^{51}$ González López, Memorias, 203.

${ }^{52}$ Shlomo Ben-Ami, The Origins of the Second Republic in Spain (Oxford: Oxford Historical Monographs, 1978), 38.
} 
exámenes finales. Los sectores liberales consideraron este artículo de la "Ley Callejo" un ultraje a la Universidad e hicieron de él bandera de sus protestas $^{53}$. En junio las movilizaciones se habían extendido por buena parte de la geografía española, al tiempo que la FUE pensaba ya en una huelga general para el inicio del nuevo curso.

En aquel contexto de efervescencia se produjo un conocido encuentro en el merendero madrileño de La Bombilla. Fue la noche del 23 de junio de 1928. Una reunión intergeneracional entre jóvenes y prometedores estudiantes de un lado e intelectuales y políticos "maduros" de otro. Promovida desde la FUE por González López, María Zambrano y José López Rey, el grupo estudiantil contó también con la presencia de Fe Sanz, Antolín Casares o Domingo Díaz Ambrona. Entre los "maduros" invitados se pudo ver a José Giral, Felipe Sánchez Román, Gregorio Marañón, Ramón María del Valle-Inclán, Ramón Pérez de Ayala, Eduardo Gómez de Baquero, Nicolás Salmerón y García, Manuel Azaña, Indalecio Prieto y Jiménez de Asúa ${ }^{54}$. No fue una reunión cualquiera. Aquella noche no se había programado evento cultural alguno ni tocaba homenaje hacia los admirados maestros. Para Zambrano, fue "un acto realmente de vanguardia" ${ }^{55}$, un llamamiento al activismo político, al esfuerzo colectivo e intergeneracional hacia "aquellos a los cuales tendríamos espontáneamente por sentirlos en el futuro de España, en nuestro futuro" ${ }^{\prime 56}$. Fue además el germen para la fundación, en octubre, de la Liga de Educación Social.

Aquel verano fue testigo del trabajo conjunto entre dirigentes estudiantiles y un pequeño grupo de intelectuales con el propósito de promover un gran movimiento renovador, aglutinador de distintas corrientes sociales - juveniles, feministas, obreras, democráticas, etc.-, y su intervención en la apática vida política nacional. En este marco de reformismo social y "horizonte de libertad", fue de nuevo la filósofa malagueña la que nos proporcionó el tono de la implicación de Asúa: "Se fundó lo que hubiera ayudado a dar la vuelta: la Liga de Educación Social. Y solamente Jiménez de Asúa quiso ser directivo por parte de los maduros. Los maduros no querían responsabilidad"57. Eran las postrimerías de 1928 . Cierto que ya se atisbaba una evolución en la actitud de la intelectualidad frente a la Dictadura en

${ }^{53}$ Ramón López Martín, Ideología y educación en la dictadura de Primo de Rivera (II) (Valencia: Universitat de València, 1995), 178.

${ }^{54}$ Jesús Moreno Sanz, "Cronología de María Zambrano", en María Zambrano. Obras Completas VI, coord. y revisión de Jesús Moreno Sanz (Madrid: Galaxia Gutenberg, 2014), 52.

${ }^{55}$ Zambrano, "Escritos autobiográficos. Delirios. Poemas. «Un Liberal»" OO. CC. VI, 731.

${ }^{56}$ Zambrano, "Delirio y destino", 867.

${ }^{57}$ Zambrano, "Escritos autobiográficos”, 732. 
cierto modo general, pero lo que acabó definiendo a este colectivo como un bloque frente al poder sería lo sucedido durante los siguientes meses, entrado ya 1929, al calor de las protestas estudiantiles ${ }^{58}$. Algunos de aquellos intelectuales, profesores de Universidad, darían entonces un paso más renunciando a sus cátedras.

\section{De dimisión a dimisión}

Con el comienzo del nuevo curso, los preparativos de huelga general de la FUE fueron cobrando forma. La respuesta del Gobierno vino con la promulgación de la Real Orden 8-II-1929, por la que se autorizaba la elaboración de listas negras de alborotadores ${ }^{59}$. Lejos de amedrentarse, los estudiantes fueron a la huelga nacional el 7 de marzo de 1929. En Madrid las protestas cobraron forma de violencia, hasta el punto que el régimen ordenó el día 11 la ocupación de las Facultades por el Ejército con el fin de controlar la entrada y salida de profesores y estudiantes. Sin embargo, incapaz de contener el empuje de las movilizaciones, mediante Real Decreto de 26 de marzo se clausuró el resto del curso académico en la capital, al tiempo que quedaban suspendidas provisionalmente las clases de muchas otras Universidades españolas.

Durante dos semanas las calles madrileñas fueron testigos de los enfrentamientos entre policía y estudiantes. La respuesta de las fuerzas del orden y el rosario posterior de sanciones y expulsiones fue la gota que colmó para que un buen puñado de catedráticos e intelectuales mostraran abiertamente su apoyo a la movilización estudiantil. Más de un centenar de profesores firmaron un escrito de protesta y cinco de ellos llegaron más lejos: José Ortega y Gasset en Madrid y Fernando de los Ríos en Granada dimitieron de sus cátedras. Pronto les siguieron Alfonso García Valdecasas, Felipe Sánchez Román y Luis Jiménez de Asúa. A partir de entonces y hasta su final, la Dictadura tuvo en los intelectuales otro foco opositor con un poderoso influjo social.

Aquella primavera de 1929 fue especialmente agitada para Asúa: apoyo incondicional del movimiento estudiantil, querella contra El Debate, conferencias, charlas... el 24 de mayo el catedrático de la Central llamó a la lucha al movimiento obrero, en un tiempo en el que la estrategia socialista pasaba todavía por una cómoda convivencia con el régimen. Y lo hizo desde un lugar tan significativo como la Casa del Pueblo de Madrid. Invitado por

\footnotetext{
${ }^{58}$ García Queipo de Llano, Los intelectuales, 544-545.

${ }^{59}$ López Martín, Ideología, 236-237.
} 
el Sindicato de Artes Blancas, aquella noche el jurista madrileño pronunció su célebre conferencia Juventud, en la que se le pudo escuchar que "el día en que las luces renovadoras encendidas por los intelectuales, los obreros y los estudiantes, se agrupen en foco convergente, en España se habrá hecho enorme y deslumbrante claridad" ${ }^{\prime \prime}$. Al respecto, cuanto menos desde el año anterior Asúa era uno de aquellos "enlaces" que venía trabajando en una eventual conjunción de fuerzas entre republicanos, movimiento estudiantil y movimiento obrero.

Poco tiempo después, en julio, abandonó Alianza Republicana al tiempo que lo hicieron Gregorio Marañón, Ramón Pérez de Ayala y Marcelino Domingo. Cuatro años después del proyecto político impulsado por Manuel Azaña, José Giral y Enrique Martí Jara, el republicanismo entró en un proceso de profunda restructuración de sus fuerzas cuya primera gran expresión fue la fundación del Partido Republicano Radical Socialista (PRRS), formación que de la mano de Marcelino Domingo y Álvaro de Albornoz nacía con el propósito de luchar por la hegemonía del republicanismo de izquierdas. Los rumores sobre el futuro político de los distinguidos dimisionarios no tardaron en aparecer y se extendió la noticia de que Jiménez de Asúa había decidido ingresar en el partido de Domingo y Albornoz. No contamos con demasiadas referencias al respecto, pero en sus Escritos Políticos Pérez de Ayala nos confesó que "ya en las postrimerías de la Dictadura, los señores Sánchez Román, Marañón, Jiménez de Asúa y yo, pensamos brindarnos como banderín de enganche o medio instrumental para dar alumbramiento de una nueva organización y generación republicana" ${ }^{61}$. Como se sabe, Asúa no ingresó entonces en ninguna formación política. Nada más lejos de sus proyecciones personales de futuro.

Aceptada su dimisión por el Ministerio de Instrucción Pública, el jurista madrileño puso de nuevo su mirada al otro lado del Atlántico. El 27 de septiembre embarcó hacia Argentina con un contrato de la Universidad de Santa Fe. A los pocos días de llegar dictaba su primer y esperado curso sobre la doctrina técnica del delito. Mientras tanto, en España, Primo de Rivera derogó por Real Decreto 21-IX-1929 el polémico artículo 53 de la "Ley Callejo". Si su intención fue la de aplacar el ímpetu de las protestas estudiantiles, nada más lejos de la realidad: con el inicio del nuevo curso regresó la rebelión en las aulas. Para comenzar, la FUE madrileña elevó al rector de la Universidad Central - y este al Gobierno- un escrito donde se exigía el levantamiento

\footnotetext{
${ }^{60}$ Luis Jiménez de Asúa, Al servicio de la nueva generación (Madrid: Javier Morata, 1930), 57.

${ }^{61}$ Ramón Pérez de Ayala, Escritos Políticos (Madrid: Alianza Editorial, 1967), 217.
} 
de las sanciones impuestas por los disturbios de marzo y la reposición de los catedráticos que habían causado baja. Receptivo con la posibilidad del regreso a sus cátedras de Ortega y Gasset y Sánchez Román, Primo de Rivera se mostró tajante con el que "consideraba el principal alentador de la protesta estudiantil de la FUE"62. Pero en aquella hora se vislumbraba en el horizonte la caída de un dictador que, enfermo y cada vez más solo, encarnaba el estertor propio del régimen.

Todo lo contrario que un movimiento opositor que se mostraba cada vez con más denuedo. El 11 de diciembre, de vuelta del país austral, más de 600 personas entre artistas, periodistas, políticos, estudiantes y amigos, asistieron al homenaje que se le brindó al jurista en el Hotel Florida de Ma$\mathrm{drid}^{63}$. Entrado el nuevo año, para el 17 de enero los representantes de la FUE se reunieron con el profesor Elías Tormo, Rector de la Universidad Central, para reiterarle sus exigencias. La respuesta que obtuvieron fue tajante: no había perdón posible ni para el dirigente estudiantil Antonio María Sbert ni para el "agitador" Luis Jiménez de Asúa, lo que de facto, en palabras de González López, "hacía inevitable la huelga estudiantil"64. La réplica del dictador disolviendo la FUE solo sirvió para mostrar con crudeza toda su debilidad. El 22 de enero estalló un paro general universitario que no tardó en extenderse desde Madrid hacia el resto de la geografía española, apoyado, esta vez sí, por las principales fuerzas obreras. Tan sólo seis días más tarde el propio militar jerezano dimitió y puso rumbo a París.

\section{Hacia la República}

Durante los días siguientes los acontecimientos se sucedieron precipitadamente: el duque de Alba, nuevo Ministro de Instrucción Pública, decretó la libertad de los estudiantes detenidos y la aprobación de los estatutos de la FUE; el 4 de febrero la Junta legítima del Ateneo exigió su inmediata restitución; el día 8 Sbert regresó de su confinamiento, mientras Jiménez de Asúa, Ortega y Gasset y Sánchez Román se reincorporaban entre vítores estudiantiles a sus cátedras; el jurista viajó poco después a Hendaya junto con Indalecio Prieto para asistir a la última cena de Unamuno en territorio francés antes de su regreso; al día siguiente una multitud recibió al profesor vasco

\footnotetext{
${ }^{62}$ González López, Memorias, 262.

${ }^{63}$ La Libertad, 12 de diciembre de 1929.

${ }^{64}$ González López, Memorias, 264.
} 
en el puente internacional de Irún; el 11 una comitiva ateneísta se reunió con el general Berenguer y el 12, repuesta la Junta legítima, se reabrió la "sede revolucionaria”...

Eran los primeros pasos de Alfonso XIII en su intento de recuperar un respaldo social que le permitiera regresar gradualmente a la senda constitucional. El decurso del año se encargó de evidenciar, como Ortega advirtió en su famoso artículo de noviembre, que el retorno a 1923 era imposible. Ya no era solo el movimiento estudiantil, el republicanismo histórico o un puñado de intelectuales los que trabajaban por el cambio del régimen. Una parte de la vieja élite política y del Ejército que habían trabajado en su sostén, la inmensa mayoría de la intelectualidad, las organizaciones obreras y el grueso de la opinión pública española manifestaron en aquella hora su divorcio con la Monarquía.

A estas alturas el movimiento estudiantil tampoco concedió tregua al Gobierno Berenguer. Es más, en certero enunciado de González Calleja, con la llegada de Berenguer "el movimiento universitario fue politizando sus acciones en sentido cada vez más inequívocamente antidinástico, hasta transformarse en uno de los protagonistas clave del enfrentamiento con el régimen"65. Al tiempo que la proyectada sublevación fue tomando cuerpo durante el otoño de 1930, los profesores más comprometidos con la revolución como Honorato de Castro, Sánchez Román y Jiménez de Asúa intensificaron sus contactos con los sectores juveniles opositores. Ni siquiera el fracaso insurreccional de diciembre y la detención de una parte del Comité Revolucionario (CR) mermaron el ánimo del movimiento. A falta de las memorias del jurista en torno a aquellas jornadas, alguien tan cercano a él como González López nos contó en las suyas:

Todos los centros de Madrid se habían convertido en focos revolucionarios. Ya no era sólo el Ateneo madrileño, el cual, desde el primer momento, había tomado la dirección de las clases intelectuales y profesionales, en Madrid, sino que ahora también los eran la Academia de Jurisprudencia, el Colegio de Abogados y cuantas sociedades eran punto de reunión de intelectuales, profesionales y estudiantes. La casa de D. Luis Jiménez de Asúa, de la cual era asiduo visitante en esos días, era para mí el principal centro de información. A ella acudía también constantemente Gregorio Marañón, que era el enlace entre los profesores, estudiantes y ateneístas, con los antiguos políticos, debatiendo ya en contra de la Monarquía y también con el gobierno, a través del Conde de Romanones ${ }^{66}$.

\footnotetext{
${ }^{65}$ González Calleja, Rebelión, 98.

${ }^{66}$ González López, Memorias, 301.
} 
Para febrero se había formado un segundo CR del que formaban parte Rafael Sánchez Guerra, Sánchez Román, Félix Gordón Ordax y el propio Jiménez de Asúa, que hizo también las veces de anfitrión para sus reunio$n s^{67}$. En un último intento por reconducir la situación política, el Rey jugó una nueva carta constitucionalista de la mano de José Sánchez Guerra. Pero el propósito del político cordobés de incorporar al nuevo Gobierno a alguno de los miembros encarcelados del CR obtuvo un rotundo fracaso. Alfonso XIII optó entonces por un Gobierno de concentración monárquica, constituido el 18 de febrero bajo la presidencia del almirante Aznar. El día anterior La Libertad publicó un artículo en el que Asúa interpretaba, en clave histórica, la sucesión de acontecimientos que se estaban produciendo: "La revolución momentáneamente sofocada palpita en cada esquina de las ciudades y sopla en los campos. Desde el levantamiento [del 12 de diciembre] ha empezado en el suelo español la guerra civil [...]. En breve plazo habrá en Europa una república más"68. Fue exactamente el mismo argumento con el que, un mes más tarde, finalizó su intervención como abogado defensor de Santiago Casares Quiroga en el Consejo de guerra contra los miembros del CR; o lo que era lo mismo: el conflicto de legitimidades estaba resuelto y por voluntad nacional en el banquillo de los acusados se sentaba el futuro Gobierno de España.

La resaca posjudicial del conocido como El gran mitin republicano de las Salesas sería larga. La sinergia entre la violencia estudiantil y la respuesta represiva de las fuerzas de orden público desembocó, en plena campaña proamnistía, en los trágicos «Sucesos de San Carlos» durante los días 24 y 25 de aquel mes de marzo. Se luchó a las puertas de la Facultad de Medicina con armas de fuego y, desde allí, los altercados se extendieron a otras zonas de la capital. Dos muertos, uno de ellos guardia civil, varias decenas de heridos y numerosas detenciones fue el saldo de aquellas dos jornadas en las que las movilizaciones se propagaron por otras ciudades españolas. Faltaban dos semanas para unas elecciones municipales que desde la acera republicana se acabó considerando en sentido plebiscitario para el futuro político de España. Tras el triunfo electoral republicano y la proclamación del régimen democrático dos días más tarde, la primera manifestación pública de Asúa fue un Mensaje a la juventud: había que formar la "retaguardia de la República".

${ }^{67}$ Eduardo González Calleja et al, La Segunda República Española (Barcelona: Pasado y Presente, 2015), 51.

${ }^{68}$ Jiménez de Asúa, “Dictablanda... Dictadura. Meditaciones de un republicano”. La Libertad, 17 de febrero de 1931. 
Mensaje a la juventud. Retorno a la ciencia

Con este elocuente título, el 17 de abril el jurista madrileño hizo un llamamiento público y en cierto modo inverso a todas aquellas invocaciones que había venido haciendo desde el comienzo de la Dictadura. El artículo apareció publicado en La Libertad, de donde era asiduo colaborador, y puede ser considerado uno de los momentos álgidos de su biografía. El motivo: una vez ganada la democracia, después de tantos años de sacrificio personal, este intelectual, científico del Derecho y profesor de Universidad con nulas aspiraciones políticas, dedica su primera manifestación pública para exhortar a las juventudes a formar la retaguardia de la República. El papel de la juventud, en ese gran proyecto colectivo de transformación de España, pasaba por regresar a Universidades y Laboratorios y elevar el país a través de la cultura y la ciencia.

Poco después de la proclamación del régimen democrático, el jurista también ingresó en la militancia del PSOE. Hacía bastantes años que sus convicciones socialistas no eran ningún secreto, pero lo que sorprendió a propios y extraños fue que algunas semanas más tarde participase como candidato para las elecciones del 28 de junio a Cortes Constituyentes. Lejos de lo que había proyectado para su futuro inmediato, nació entonces una carrera política de la que pronto escribiría su primera gran página, cuando a mediados de julio el Congreso lo nombró Presidente de la Comisión constitucional ${ }^{69}$. Pero, si tanto le costó dar el salto al gran ruedo de la política nacional, cuando lo hizo fue bajo los signos de la condicionalidad y la temporalidad. Asúa nunca tuvo intención de hacer carrera política. Asumió una responsabilidad temporal para colaborar en el fortalecimiento institucional de la República, en su institucionalización bajo la voluntad revolucionaria de transformar España por el camino de la democracia. Un compromiso, en última instancia, con un pueblo ejemplar -así lo definió en otro artículo de referencia publicado en La Libertad el 13 de mayo-, verdadero protagonista del cambio y del que debían emanar todos los poderes del nuevo Estado.

Su intención continuó siendo la de regresar, más pronto que tarde, a su vida académico-intelectual. No en vano, aquellos años fueron también los de su tránsito hacia la dogmática a través de la teoría jurídica del delito, en tanto que "la dogmática llegó de la mano de la política; una vez que la dictadura

${ }^{69}$ Su trayectoria al frente de aquella comisión continúa mereciendo el interés de historiadores y juristas, como demuestra el último artículo de Enrique Roldán Cañizares: "Luis Jiménez de Asúa: un penalista a cargo de la Constitución de la II República”, Historia Constitucional, 21 (2020): 473-509. 
facciosa había caído y se había alcanzado un régimen capaz de modernizar España, se hacía necesario abandonar las ilusiones de sociedades futuras, poner los pies en la tierra y apuntalar las conquistas jurídicas y democráticas de la II República"70. Al respecto, su discurso de apertura del curso académico en la mañana del 1 de octubre de 1931 quedó grabado en la memoria colectiva de algunos de los presentes y ha sido evocado por otros muchos durante décadas. Significó la viva expresión del punto de inflexión definitivo en la orientación científica del jurista hacia la dogmática, apuntada ya dos años antes con sus ponencias sobre La doctrina técnica del delito en la Universidad de Santa Fe. La trascendencia del momento histórico para la evolución del penalismo de habla castellana durante el siglo pasado es materia de consenso dentro del ámbito del Derecho.

Sobrepasando, para terminar, el marco cronológico propuesto inicialmente, el ascendiente de Asúa entre las jóvenes promociones universitarias continuó indeleble en el decurso del nuevo régimen, pero tuvo su reverso de la moneda en la animadversión que suscitó entre las renovadas formaciones conservadoras o de extrema derecha. En un contexto de agitación en el que se fueron adueñando de la vida universitaria los grupos más extremistas de uno y otro signo, los incidentes de Asúa fueron creciendo en asiduidad y envergadura $^{71}$. El propio protagonista terminó advirtiendo de la deriva de la juventud en un escenario tan particular como la Escuela de Verano Socialista de Torrelodones de 1933. Aún más, la mañana del 12 de marzo de 1936 los estudiantes falangistas Alberto Aníbal, José María Díaz Aguado, Alberto Ortega y Guillermo Aznar, todos militantes del Sindicato Español Universitario (SEU), atentaron contra su vida a la salida de su domicilio en la calle Goya. Con bastante suerte salvó la vida pero no así su joven escolta, Jesús Gisbert, que murió horas más tarde por la gravedad de las heridas de bala. Los días siguientes, como se sabe, se precipitaron los acontecimientos con la ilegalización de Falange y las detenciones de José Antonio Primo de Rivera, buena parte de su Junta Política y un buen número de los dirigentes más destacados del SEU.

${ }^{70}$ Roldán Cañizares, Derecho Penal, 171. Además de la citada obra, una síntesis de la importancia del momento para la trayectoria científica de Asúa en su camino hacia la dogmática jurídico-penal en: Hans-Heinrich Jescheck, "El significado de don Luis Jiménez de Asúa en la dogmática española en el campo de la teoría jurídica del delito", Revista de la Facultad de derecho de la Universidad Complutense, extra 11 (1986), 397-408.

${ }^{71}$ Muchos pueden seguirse a través de la hemeroteca de época y de un buen número de ellos da cuenta el profesor José María Puyol Montero en "La Facultad de Derecho de la Universidad Central en sus actas (1931-1936)", en La Universidad Central durante la Segunda República, ed. Eduardo González Calleja y Álvaro Ribagorda (Madrid: Universidad Carlos III, 2013): 301-322. 


\section{Conclusiones}

De entre todos los vectores que conforman la trayectoria pública de Luis Jiménez de Asúa, su compromiso con la problemática universitaria resulta, además de incontrovertible, una constante de principio a fin: en 1915 se estrenó como profesor auxiliar en la Universidad Central; en 1918 ganó cátedra por oposición en su Facultad de Derecho y al año siguiente, cuando un Real Decreto impulsó el desarrollo del asociacionismo estudiantil con el propósito de encauzar su participación en la vida universitaria, el joven catedrático se prodigó en el apoyo de las Asociaciones Oficiales no confesionales en su desafío de disputarle el monopolio de la representatividad estudiantil a las organizaciones católicas. Un ejercicio de prolongación de esta secuencia cronológica hasta el final de sus días nos conduciría sin equívoco a su constatación plena, primero en España y más tarde durante su exilio argentino. Sus conferencias, sus publicaciones sobre los problemas de la Universidad argentina, sus dimisiones en respuesta a las políticas intervencionistas de las autoridades y el polo de atracción juvenil en el que se convirtió su propio domicilio en la capital bonaerense dan testimonio de ello.

Más allá de las innovaciones metodológicas que introdujo en las aulas españolas de la época y de sus primeras publicaciones científicas, su presencia en la vida pública nacional durante sus primeros años de magisterio se circunscribe a la lucha por la renovación de la Universidad. Al respecto, jugó un papel destacado en la llegada a España del movimiento renovador que desde su epicentro en la Universidad de Córdoba se extendía por distintas latitudes latinoamericanas. Asumió un papel de mediador distinguible sin demasiado esfuerzo desde su primer viaje trasatlántico de 1923 y su discurso resultante: Impresiones de la Argentina.

En el ínterin de aquel viaje sobrevino el golpe militar de septiembre. Siendo materia de consenso el punto de inflexión que supuso para la movilización estudiantil la actitud intervencionista y sectaria que caracterizó al régimen primorriverista desde primera hora, para Jiménez de Asúa — sin soslayar el problema que puede plantear la imprecisión de "fronteras cronológicas" que presenta la vida de toda persona-implicó el comienzo de una nueva etapa, y de una nueva actitud política, inteligible como punto de partida del profundo proceso de maduración personal que experimentó durante la década de los veinte. Su primera expresión fue precisamente su toma de posición ante la nueva realidad política del país. El joven catedrático, cuyo reconocimiento como penalista comenzaba entonces a traspasar fronteras, no se mostró ni vacilante, ni expectante ni reservado como buena parte de la intelectualidad española. Desde el comienzo Asúa formó parte del —en sus 
inicios - reducido sector intelectual que se mostró acérrimo enemigo de la Dictadura. Las denuncias ante la fiscalía, las detenciones, el confinamiento, las suspensiones, las prohibiciones, las censuras, etc. fueron la respuesta del régimen a una actitud de enérgica insurgencia.

Pero de la misma manera que ocurrió con las reivindicaciones juveniles, en la lucha personal de Asúa desde entonces hasta la proclamación de la Segunda República se distinguen una serie de estadios. Ambos tienen puntos de convergencia inequívocos. El ascendiente del penalista entre los sectores estudiantiles progresistas se explica fundamentalmente por lo que representó: un jovencísimo catedrático con una actitud insurreccional contra el poder dictatorial y con ideas transgresoras hablando a legiones de estudiantes faltos de referentes que sentían respirar una atmósfera rupturista. No extraña en este sentido que la primera convocatoria de huelga general de la FUE, en mayo de 1928, fuese la respuesta a la sanción de un mes de empleo y sueldo para nuestro protagonista por su conferencia en la Universidad de Murcia. La coyuntura marcó, como bien ha sido entendido por la historiografía, el tránsito de la reivindicación corporativa a la protesta política del movimiento estudiantil. Una circunstancia que tuvo su punto de no retorno con las protestas generalizadas de marzo de 1929 y sus manifestaciones de creciente violencia, impregnadas además de un sentido inequívocamente antidinástico.

Para Jiménez de Asúa fue la hora de llevar más lejos su lucha personal: a sus ya clásicas arengas, el empleo de su cátedra como plataforma hacia la disidencia y su implicación activa en iniciativas juveniles como la Liga de Educación Social, sumó entonces el papel de "enlace" para la conjunción de las distintas fuerzas republicanas, estudiantiles y obreras. Si el 24 de mayo llamó a la lucha al movimiento obrero en su conocida conferencia de la Casa del Pueblo de Madrid, días más tarde presentó su dimisión como catedrático en respuesta a los excesos en la represión de las fuerzas del orden contra los estudiantes. Algunas semanas después abandonó Alianza Republicana, en un momento decisivo en la reestructuración de unas fuerzas republicanas que hasta el momento no habían mostrado ni de cerca el poder de convocatoria y movilización contra la Dictadura que exhibía la juventud universitaria española. Lejos de desaparecer, con la caída del dictador se intensificaron las protestas estudiantiles contra la Monarquía, al tiempo que los profesores más comprometidos con la causa revolucionaria - entre ellos Asúa- fortalecían los vínculos con sus dirigentes más destacados.

El protagonismo del movimiento estudiantil en la caída definitiva de la Monarquía es bien conocido. En última instancia, su activismo fue la viva expresión de una progresiva toma de conciencia colectiva durante la década anterior que fue transformando la reivindicación corporativa en protesta 
política. El tono general de exigua oposición político-social ante el régimen autoritario de Primo de Rivera fue roto en primera instancia por los estudiantes. En aquella hora, Jiménez de Asúa asumió un papel de "mediador ideológico" entre estos y el movimiento de reforma que desde la Universidad argentina de Córdoba se fue extendiendo por el continente americano bajo la bandera de la autonomía y democratización de la vida universitaria. Pero las protestas por la problemática universitaria trascendieron en su componente social como consecuencia de la revolución de valores por la que atravesaba la juventud escolar. Sus protagonistas atribuyeron al joven catedrático madrileño un cierto liderazgo, bien definido por tres vectores: 1. Su fe ciega en la juventud como motor de cambio. 2. La vehemencia con la que sostuvo su disidencia frente al régimen. 3. La defensa de nuevos valores sociales, vivo testimonio de subversión frente a los usos y costumbres más tradicionales.

Al final de la década y durante el comienzo de la siguiente, Asúa asumió entonces un papel de enlace para la consolidación de la alianza entre los estudiantes opositores y el movimiento obrero, notablemente escenificada en las protestas generales - paréntesis aparte tras el fracaso de la insurrección de Jaca y las vacaciones de Navidad- de finales de 1930 y comienzos de 1931. Tras el 14 de abril, Jiménez de Asúa entendió que la transformación del país por la vía democrática requería, entre otras cuestiones, de la "desmovilización política" de estudiantes y profesores en aras de elevar el país a través de la cultura y la ciencia. Es bien sabido que esta no se produjo. Incluso su futuro inmediato viró inopinadamente cuando se le planteó una gran disyuntiva: "replegarse" — como tenía planeado- a su cátedra, o participar - por compromiso y aptitudes- en la institucionalización del nuevo régimen democrático.

\section{Fuentes archivísticas}

AGUCM Archivo General Universidad Complutense de Madrid

AFPI Archivo de la Fundación Pablo Iglesias (Alcalá de Henares).

AHRTA Archivo Histórico de Radio y Televisión Argentina.

\section{Bibliografía}

BALLBÉ, MANUEL. Orden público y militarismo en la España constitucional (1812-1983). Madrid: Alianza Editorial, 2ª ed., 1985. 
BARRACHINA, MARIE-ALINE. "Maternidad, feminidad, sexualidad. Algunos aspectos de las primeras jornadas eugénicas españolas (Madrid, 1928-Madrid, 1933)". Hispania, LXIV/3, no 218 (2004): 1003-1026.

BÉCARES BOTAS, VICENTE. "Una carta desconocida de Unamuno a Jiménez de Asúa”. Ínsula no 493 (1987).

BEN-AMI, SHLOMO. "Los estudiantes contra el Rey. Papel de la F.U.E. en la caída de la Dictadura y la proclamación de la República”. Historia 16, Año I, no. 6 (octubre 1976): 37-47.

BEN-AMI, SHLOMO. The Origins of the Second Republic in Spain. Oxford: Oxford Historical Monographs, 1978.

BEN-AMI, SHLOMO. Los orígenes de la Segunda República Española: anatomía de una transición. Madrid: Alianza Editorial, 1990.

CARREÑO, LUCIANA. "Relaciones culturales hispanoargentinas en la década del veinte. Universitarios, intelectuales y maestros, un diálogo a través de las revistas estudiantiles". Revista Circunstancia, Año X, 28 (mayo, 2012).

CHAVES PALACIOS, JULIÁN. "Oposición política a la monarquía de Alfonso XIII. José Giral y los republicanos en la Dictadura de Primo de Rivera". Hispania no 252 (enero-abril, 2016): 159-187.

FERNÁNDEZ MARRÓN, ICÍAR. "Cartas de cuatro juristas republicanos a Miguel de Unamuno (1920-1936)". Cuadernos de la cátedra de Miguel de Unamuno, 33, Universidad de Salamanca (1998): 193-218.

GARCÍA QUEIPO DE LLANO, GENOVEVA. Intelectuales y política en la dictadura de Primo de Rivera. Tesis doctoral. Madrid: Universidad Complutense, 1987.

GARCÍA QUEIPO DE LLANO, GENOVEVA. Los intelectuales y la dictadura de Primo de Rivera. Madrid: Alianza Editorial, 1988.

GONZÁLEZ CALLEJA, EDUARDO. Rebelión en las aulas. Madrid: Alianza Editorial, 2009.

GONZÁLEZ CALLJEJA, EDUARDO ET AL. La Segunda República Española. Barcelona: Pasado y Presente, 2015.

GONZÁLEZ LÓPEZ, EMILIO. El espíritu universitario. Madrid: Javier Morata, 1931.

GONZÁLEZ LÓPEZ, EMILIO. Memorias de un estudiante liberal (1903-1931). A Coruña: Ediciós do Castro, 1987.

JATO, DAVID. La rebelión de los estudiantes. Madrid: Imp. Romero-Requejo, 1968.

JESCHECK, HANS-HEINRICH. "El significado de don Luis Jiménez de Asúa en la dogmática española en el campo de la teoría jurídica del delito". Re- 
vista de la Facultad de derecho de la Universidad Complutense, extra 11 (1986): 397-408.

JIMÉNEZ DE ASÚA, LUIS. "La esterilización de los anormales y delincuentes incorregibles". Revista de Ciencias Jurídicas y Sociales no 1 (enero-marzo, 1918): 23-38.

JIMÉNEZ DE ASÚA, LUIS. El Derecho penal en la República del Perú. Valladolid: Sección de Estudios Americanistas de la Universidad de Valladolid, serie $2^{a}$, número III, 1926.

JIMÉNEZ DE ASÚA, LUIS. Política. Figuras. Paisajes. Madrid: Historia Nueva, 1927.

JIMÉNEZ DE ASÚA, LUIS. Endocrinología y Derecho penal. Eutanasia y Homicidio por compasión. Dos conferencias pronunciadas en la Facultad de Derecho de la Universidad de Montevideo. Montevideo: Anales de la Universidad, Imprenta Nacional, 1927.

JIMÉNEZ DE ASÚA, LUIS. Juventud. Conferencia de Luis Jiménez de Asúa y réplica de José López-Rey. Madrid: Velasco, 1929.

JIMÉNEZ DE ASÚA, LUIS. Libertad de amar y derecho a morir. Madrid: Historia Nueva, 1929.

JIMÉNEZ DE ASÚA, LUIS. Notas de un confinado. Madrid: Mundo Latino, 1930.

JIMÉNEZ DE ASÚA, LUIS. Al servicio de la nueva generación. Madrid: Javier Morata, 1930.

LÓPEZ MARTÍN, RAMÓN. Ideología y educación en la dictadura de Primo de Rivera (II). Valencia: Universitat de València, 1995.

MARTÍNEZ CÁNOVAS, GONZALO J. “Luis Jiménez de Asúa. El penalista de la retaguardia imposible". Tesis doctoral. Alicante: Universidad de Alicante, 2020.

MARTÍNEZ RIAZA, ASCENSIÓN. "Las cicatrices de Ayacucho. España en la celebración de un centenario hispanoamericano". Anuario IEHS: Instituto de Estudios histórico sociales, 32, no 1 (2017): 179-204.

MORA MOLINA, JUAN JESÚS. Derecho a la vida y permiso para destruir «vidas sin valor». Sevilla: Aconcagua Libros, 2002.

MORENO SANZ, JESÚS. "Cronología de María Zambrano". En OO. CC. VI, editado por Goretti Ramírez y Jesús Moreno Sanz. Barcelona: Galaxia Gutenberg, 2014.

PÉREZ DE AYALA, Ramón, Escritos políticos. Madrid: Alianza Editorial, 1967. PUYOL MONTERO, JOSÉ MARÍA. "La Facultad de Derecho de la Universidad Central en sus actas (1931-1936)". En La Universidad Central durante la Segunda República, ed. Eduardo González Calleja y Álvaro Ribagorda. Madrid: Universidad Carlos III, 2013. 
ROLDÁN CAÑIZARES, ENRIQUE. Luis Jiménez de Asúa. Derecho penal, República, Exilio. Madrid: Dykinson, 2019.

ROLDÁN CAÑIZARES, ENRIQUE. “De Berlín a Buenos Aires: el trasplante del método de casos en Argentina". En La memoria del jurista español, ed. Manuel Ángel Bermejo Castrillo. Madrid: Dykinson, 2019: 383-416.

ROLDÁN CAÑIZARES, ENRIQUE. "Luis Jiménez de Asúa: Un penalista a cargo de la Constitución de la II República”. Historia Constitucional, 21 (2020): 473-509.

RIVACOBA Y RIVACOBA, MANUEL DE. "El Derecho penal en el mundo hispánico antes y después de Jiménez de Asúa”. Revista de la Facultad de Derecho de la Universidad Complutense, 11 (junio, 1986): 263-277.

SOLDEVILLA, FERNANDO. El Año Político. Madrid: Imprenta y encuadernación de Julio Cosano, 1927.

TUÑÓN DE LARA, MANUEL. El movimiento obrero en la historia de España. Madrid: Taurus, 1972.

URBINA TORTELLA, SEBASTIÁN. Ética y política en Jiménez de Asúa. Palma de Mallorca: Facultad de Derecho, 1984.

VALENCIANO GAYÁ, LUIS. El Rector Loustau y la Universidad de Murcia. Madrid: Academia Alfonso X el Sabio, 1979.

VIDARTE, JUAN SIMEÓN. No queríamos al Rey. Barcelona: Grijalbo, 1977.

ZAMBRANO, MARÍA. "Delirio y destino". En OO. CC. VI, editado por Goretti Ramírez y Jesús Moreno Sanz. Barcelona: Galaxia Gutenberg, 2014.

ZAMBRANO, MARÍA. "Escritos autobiográficos. Delirios. Poemas. «Un Liberal»”. En OO. CC. VI, editado por Goretti Ramírez y Jesús Moreno Sanz. Barcelona: Galaxia Gutenberg, 2014. 